\title{
Subsurface Gasoline "Blending" and Forensic Implications
}

\author{
Jun Lu',2 \\ ${ }^{1}$ AECOM, Long Beach, CA, USA \\ ${ }^{2}$ China Aerospace Kaitian Environmental Technology Co. Ltd., Changsha, China \\ Email: lujun21@yahoo.com
}

How to cite this paper: Lu, J. (2017) Subsurface Gasoline "Blending" and Forensic Implications. Journal of Environmental Protection, 8, 714-732.

https://doi.org/10.4236/jep.2017.86046

Received: May 9, 2017

Accepted: June 24, 2017

Published: June 27, 2017

Copyright (c) 2017 by author and Scientific Research Publishing Inc. This work is licensed under the Creative Commons Attribution International License (CC BY 4.0).

http://creativecommons.org/licenses/by/4.0/

\section{(c) (†) Open Access}

\begin{abstract}
At petroleum refining facilities with a long operational history, it is likely that some products were released to the subsurface and migrated to the water table. At or near the water table, these products might have commingled with a pre-existing light non-aqueous phase liquid (LNAPL) plume(s). Depending on the types of products involved and site hydrodynamics, commingling might result in the formation of a "new" LNAPL that exhibits similar characteristics to products that were manufactured via intentional blending by refinery operations. This study presents a case in which subsurface commingling of two intermediate gasoline-range products occurred at a petroleum refinery. The commingled "new" product appears almost identical to finished gasoline. As the intermediate stream products are typically sourced from refinery and finished products from either refinery or other sources (e.g., pipeline corridors), distinction of the commingled gasoline intermediate stream product from finished gasoline becomes critical not only for resolving liability issues, but also development of a remedial strategy. In this study, the source relationship between the gasoline-range intermediate stream product and finished gasoline was resolved using multiple lines of evidence including a gasoline additive, LNAPL chromatograms, diagnostic compounds (biomarkers) and ratios, and site LNAPL hydrodynamics.
\end{abstract}

\section{Keywords}

Petroleum Refining, Gasoline Intermediate Stream Products, Gasoline Blending, LNAPL Comingling, LNAPL Source Identification

\section{Introduction}

Hundreds of intermediate stream products are generated from relatively limited types of crude oil at major petroleum refineries. This paper opens with an in- 
troduction of basic concepts of petroleum refining and gasoline blending processes, and is followed by descriptions of petroleum releases of petroleum products and a discussion of subsequent subsurface commingling. A case study is then presented in which two gasoline intermediate stream products were released, migrated to the water table, and then commingled in right proportions to result in a type of LNAPL that resembled a finished gasoline. As a major pipeline corridor runs by the area and some of the pipelines carried finished gasolines in the past, distinction of the gasoline-range intermediate stream products from finished gasoline was critical to understand the source relationship, which helps not only for liability resolution, but also remedial strategy development.

\section{Petroleum Refining and Gasoline Blending Basics}

Crude oil is not generally useful. The objective of refining is to turn the crude into useful products such as gasoline, kerosene, diesel, lubricants and feedstock in petrochemical processes. Figure 1 is a schematic of the change of relative proportions of each type of product from crude to refined products. As can be observed, in a typical type of raw crude, predominant hydrocarbons are in gasoil range (i.e., composed predominantly of heavy hydrocarbons), with some diesel, jet fuel, and gasoline. The refinery converts raw crude into products that are dominantly gasoline that lack gasoil

The refining process starts with crude distillation, followed by a number of processes such as cracking, reforming, isomerization, and alkylation to produce various intermediate stream products. Distillation/fractionation separates crude oil into various "cuts" that are defined by their boiling points. Cracking breaks larger molecules into smaller ones. Reforming converts naphthenes into aromatics or normal paraffins into branched paraffins. Isomerization converts paraffins into isoparaffins. Alkylation combines two loweroctane molecules into one higher octane molecule. In simple terms, refining processes separate, reshape and resize the molecules to convert the entire barrel to high value products [1].

Blending is the process that combines intermediate stream products and additives in various proportions resulting infinished products that meet regulatory/

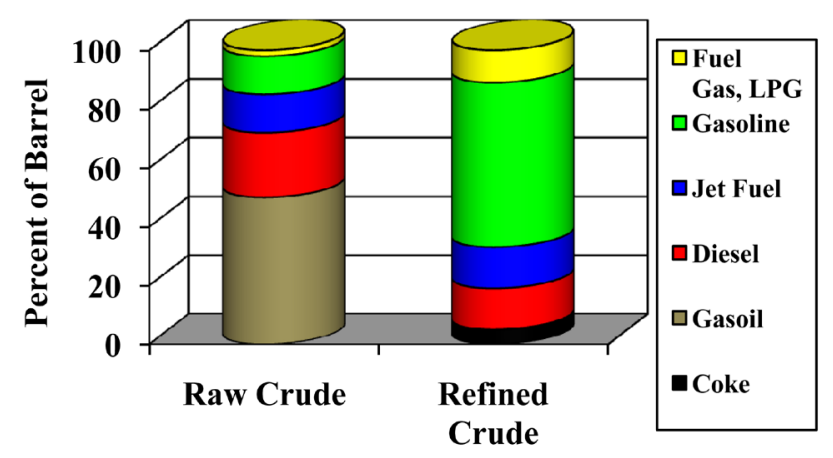

Figure 1. Comparison of hydrocarbon make-ups before and after refining a crude (After a presentation by B. Martin, 2010). 
market specifications. In this process, gasoline blending is probably the most complex. There are two very important requirements that need to be met for each gasoline blend. One is Reid vapor pressure (RVP) and the other isoctanenumber. The RVP is the vapor pressure of the gasoline blend when the temperature is 100 degrees Fahrenheit and varies between summer (lower) and winter (higher). In a gasoline blend, each compound contributes to the RVP, but major contribution results from light-end hydrocarbons (i.e., butane, pentane, and isopentane) that exhibit the highest vapor pressures.

Octane numbers are measures of whether a gasoline will cause knocking in an engine and defined as the percent of isooctane in the isooctane/normal heptane blend that knocks at the same compression ratio as the gasoline [2]. The octane numbers of the refinery intermediate stream products vary depending on the components of the stream. Straight-run gasoline has a very low octane number (63) and was only used as bulk component for gasoline produced in or prior to the 1970s when lead was added to boost the octane number. Reformate (a stream composed predominantly of mono-aromatic compounds) has a much higher octane number (89) and is used as one of the major blending components in modern gasoline. Alkylate (a stream composed of predominantly isooctane) has the highest octane number (96) and is used to boost the octane number in moderngasoline. There are many other types of intermediate stream products with octane numbers that fall within this range; these products are used as gasoline blending components. As such, the same octane number of gasoline can have different blends of intermediate stream products. As an example, two gas chromatography/flame ionization detection (GC/FID) chromatograms are shown in Figure 2 representing two types of fresh modern gasolines. Figure 2(a) is a type of regular gasoline, which is characterized predominantly by isopentane, pentane, 2-methalpentane and aromatic compounds (toluene, xylenes and 1,2,4trimethylbenzene). Figure $2(\mathrm{~b})$ is a fresh premium gasoline. The chromatographic pattern appears different, but it contains the same suite of major compounds. The difference is that isooctane is added to boost up the octane number to meet specification of premium gasoline.

\section{Releases of Petroleum Products and Subsequent Subsurface Commingling}

As described above, petroleum refining is a complex process. A refinery with an extensive product linetypically has hundreds to thousands of miles of pipelines, tens to hundreds of storage tanks, numerous pumps, and related equipment. Most refineries were constructed prior to 1970s, the pipelines are mostly underground, and the storage tanks are single-bottomed. At these facilities, some of the products were likely released to the subsurface.

Figure 3 shows a typical release of LNAPL at the ground surface. The LNAPL flows downward through the vadose zone due to gravity and capillary forces. Along its downward path, the LNAPL is likely influenced by geologic stratigraphy and/or hydrologic gradients it encounters; and eventually finds its way to 


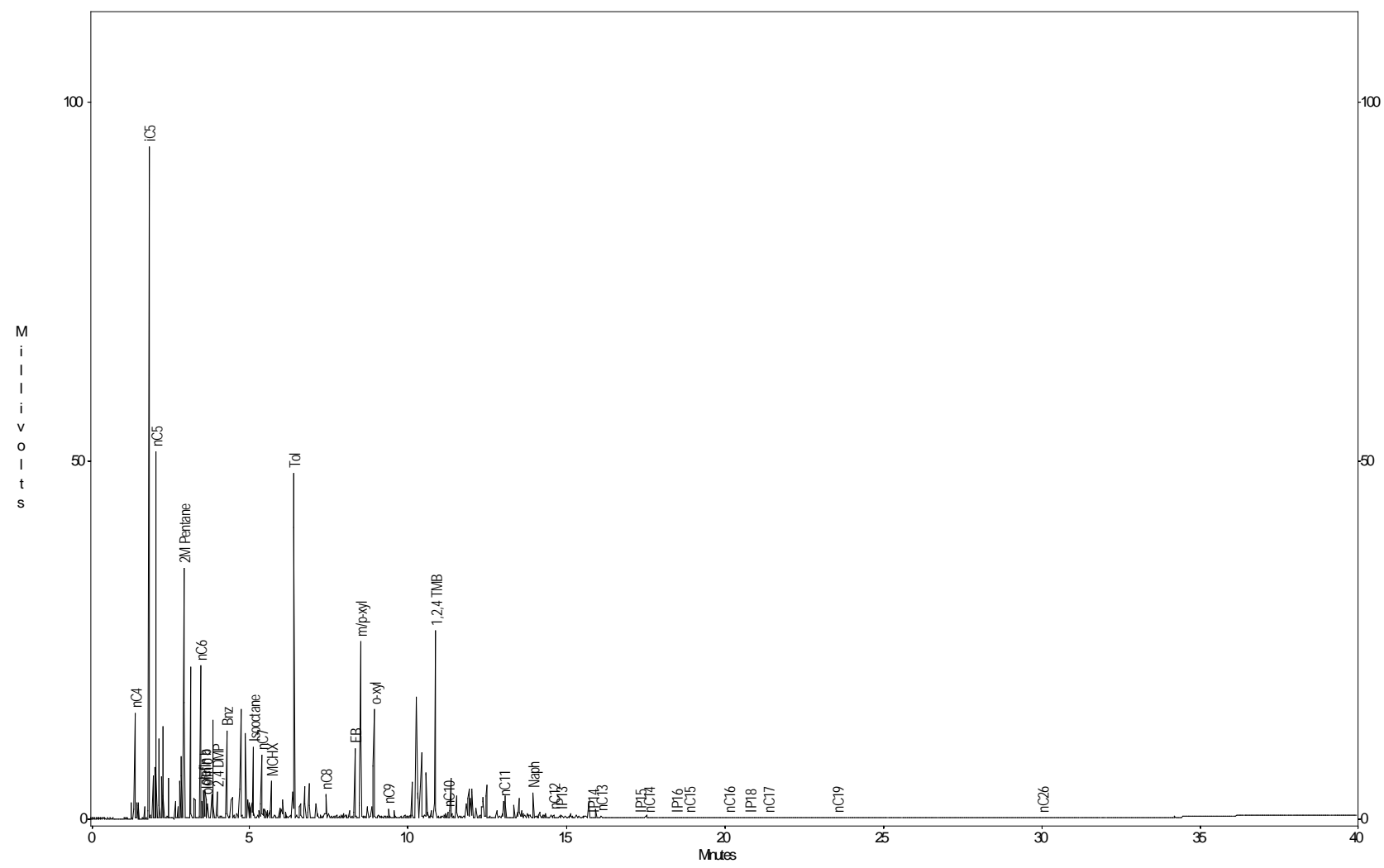

(a)

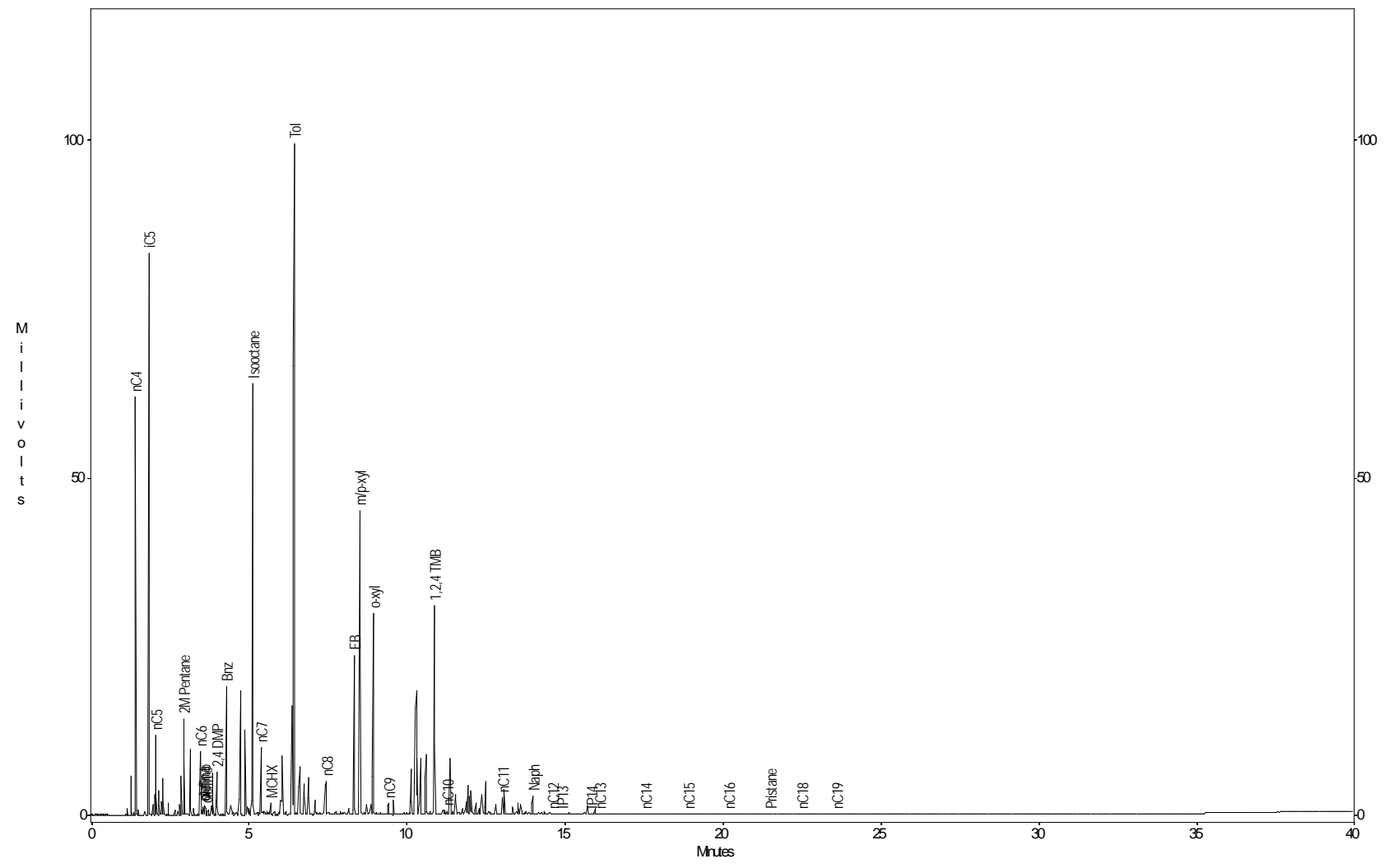

(b)

Figure 2. GC/FID chromatograms of typical modern gasolines ((a) regular; (b) premium). The samples were collected from an anonymous refinery. 


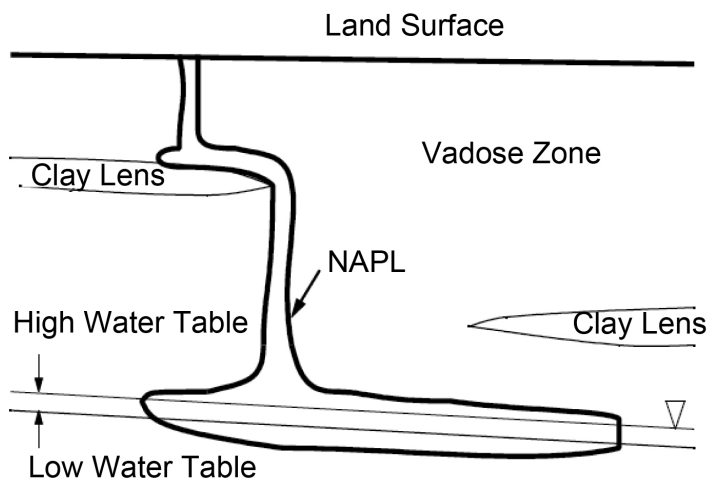

Aquifer

Figure 3. Schematic view of LNAPL release and migration pathway [3].

the water table. Upon entering the water table, the LNAPL may continue to migrate if sufficient head is present.

Figure 4 presents two examples of gasoline-range intermediate stream products and similar types of LNAPL. Figure 4(a) is a chromatogram of light hydrocrackate product, which is the lightest "cut" from ahydrocracking unit. Figure 4 (b) is the similar product that was found in groundwater. Figure $4(\mathrm{c})$ is a chromatogram of reformate, a type of intermediate stream product from reformer unit. Figure 4 (d) is the similar product on groundwater. Note that in the LNAPL samples, minor amounts of heavier hydrocarbons are also present. These hydrocarbons are from middle distillate intermediate stream(s) known to be released to the subsurface historically [5]. Weathering was considered to be a possible mechanism for the presence of heavier hydrocarbons; however, it is not a significant factor in this study area due to the depth of LNAPL occurrence ( $>50$ feet below surface) and the fine grained geological materials (predominantly silt and clay) above the water table.

In this study, comparison between the fresh intermediate stream products and the LNAPLs was made based on the hydrocarbon range and types of major compounds in the samples. The feed stocks used for the refining processes may differ between the current fresh stream and the stream manufactured historically. In addition, weathering may alter relative proportion of the major compounds in the LNAPL. However, as a refining process was set up to produce intermediate stream products that bear some general characteristics (i.e., the hydrocarbon range and types of major compounds), the general similarity of the two aspects, combined with understanding of the site history suffices to relate the LNAPLs to likely refinery intermediate stream products.

At these facilities, numerous extraction wells were used to remove LNAPLs from the subsurface. Cones of depression developed from pumping of these 


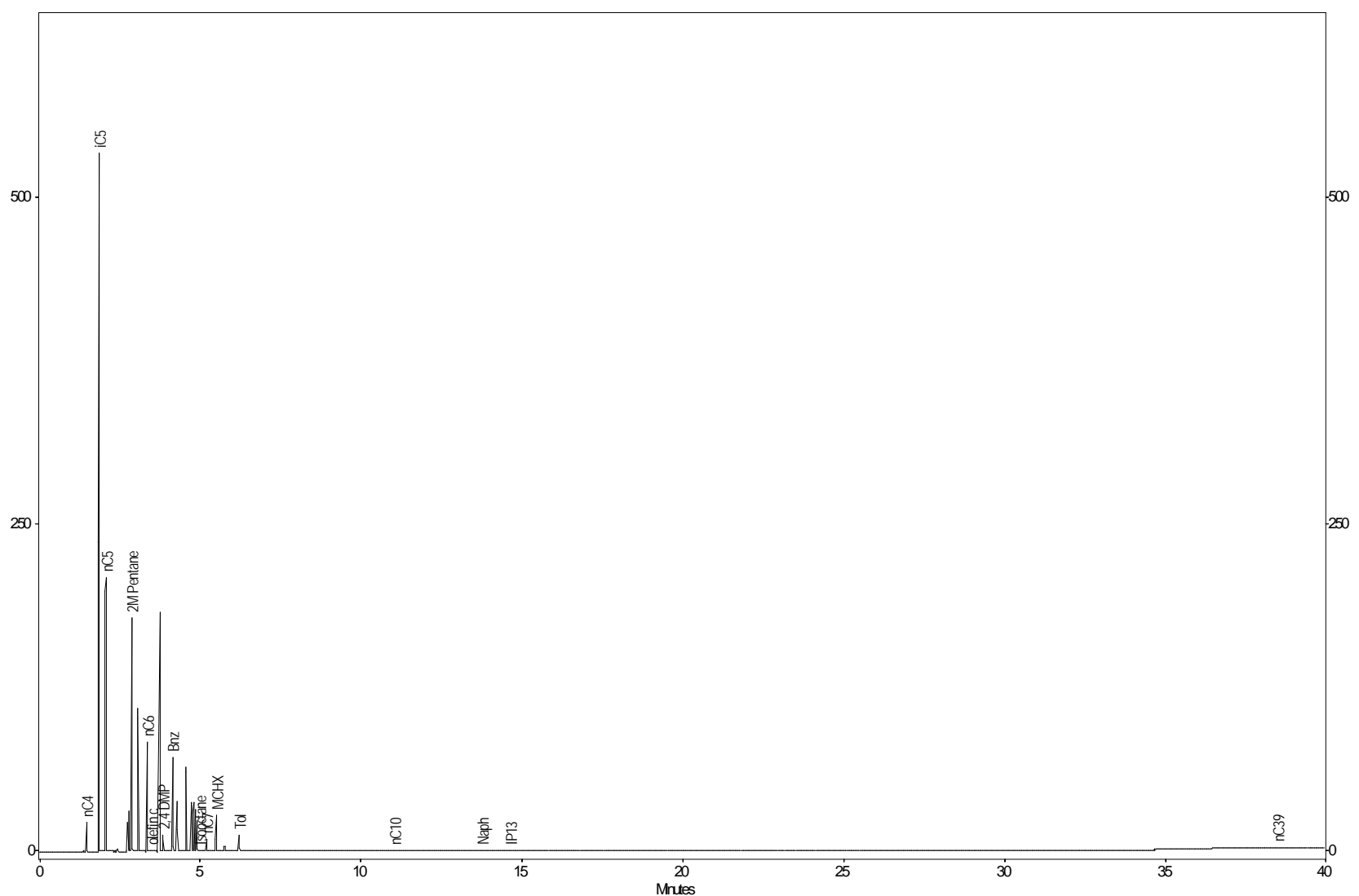

(a)

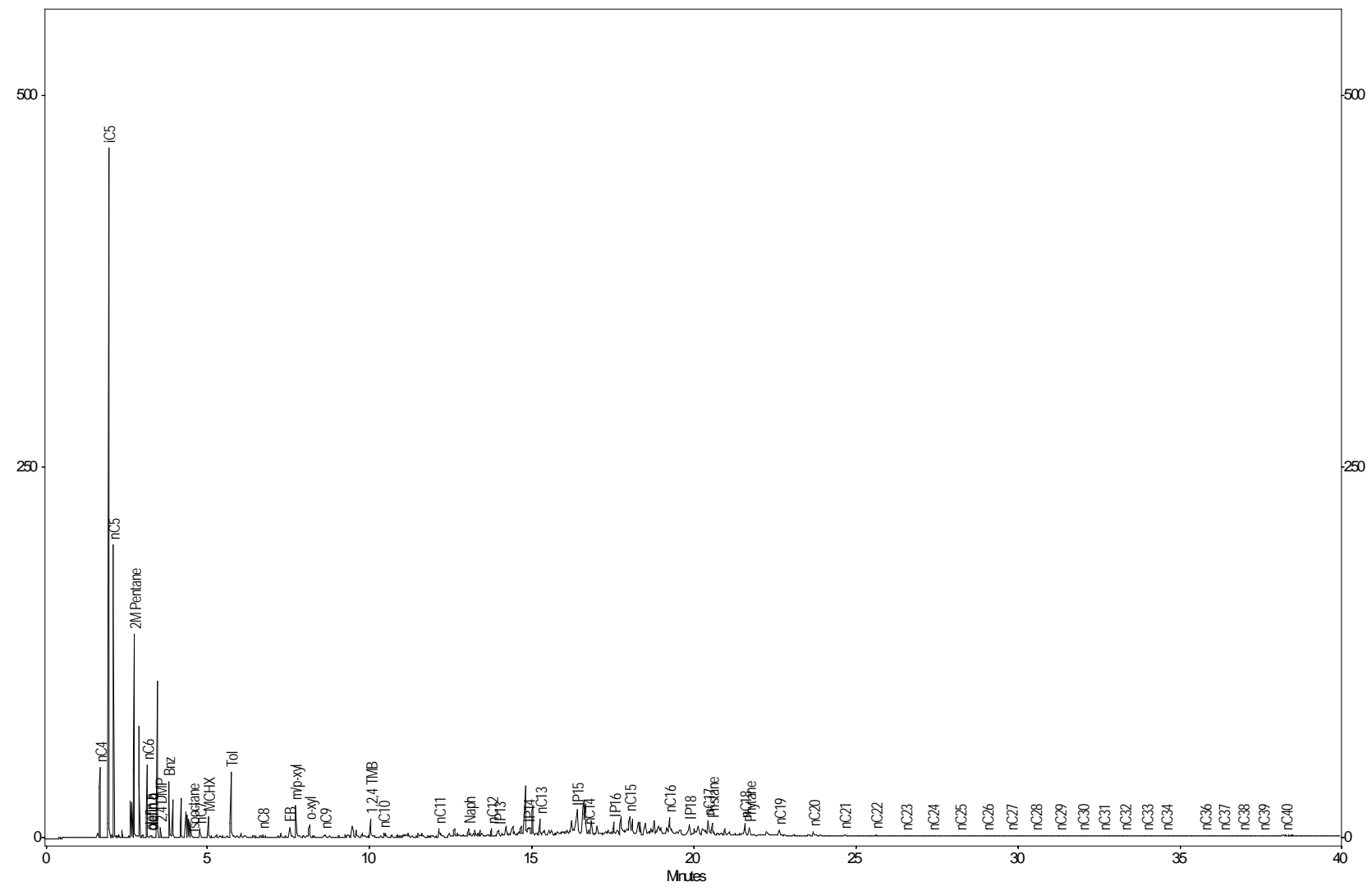

(b) 
J. Lu

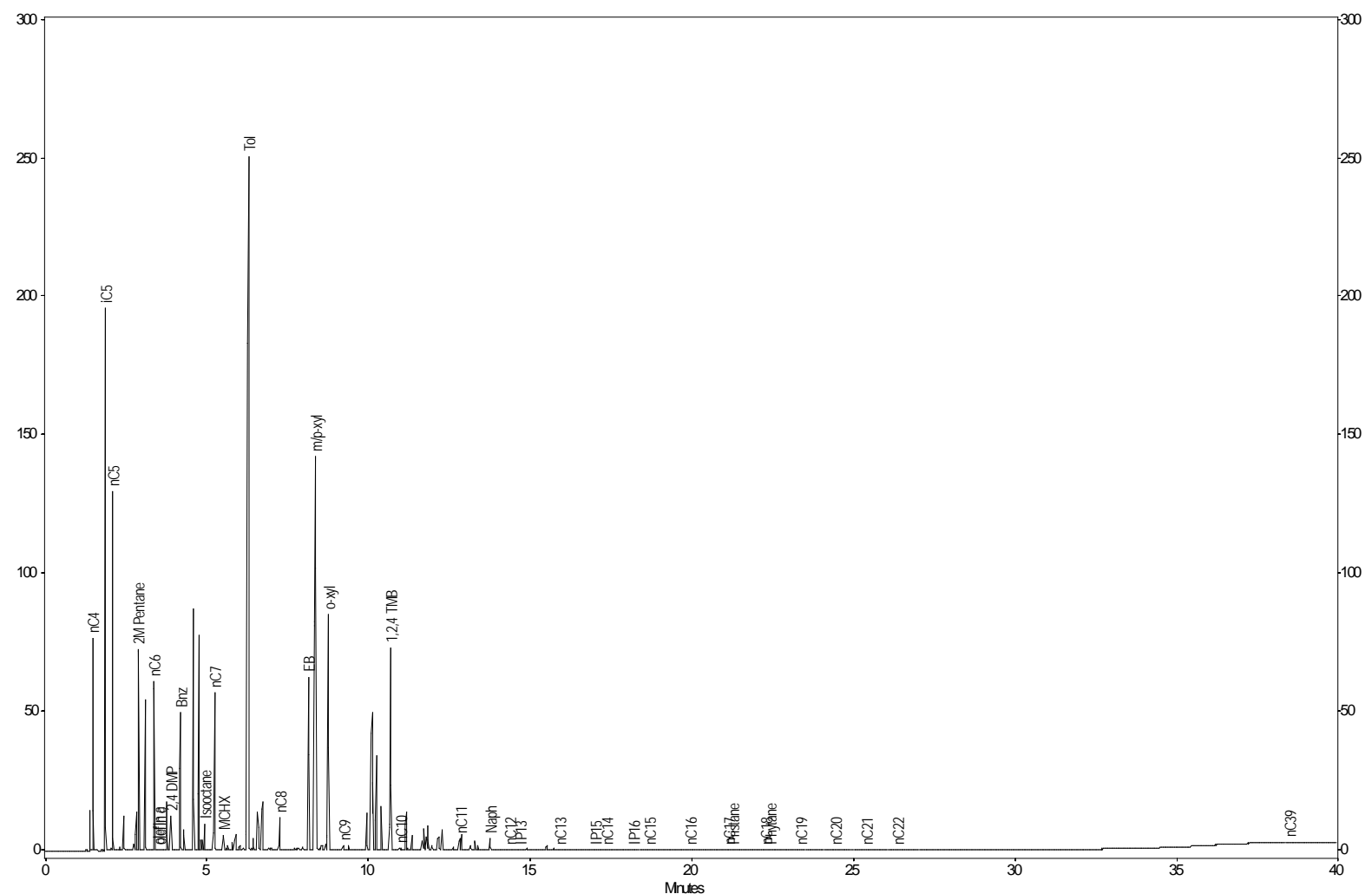

(c)

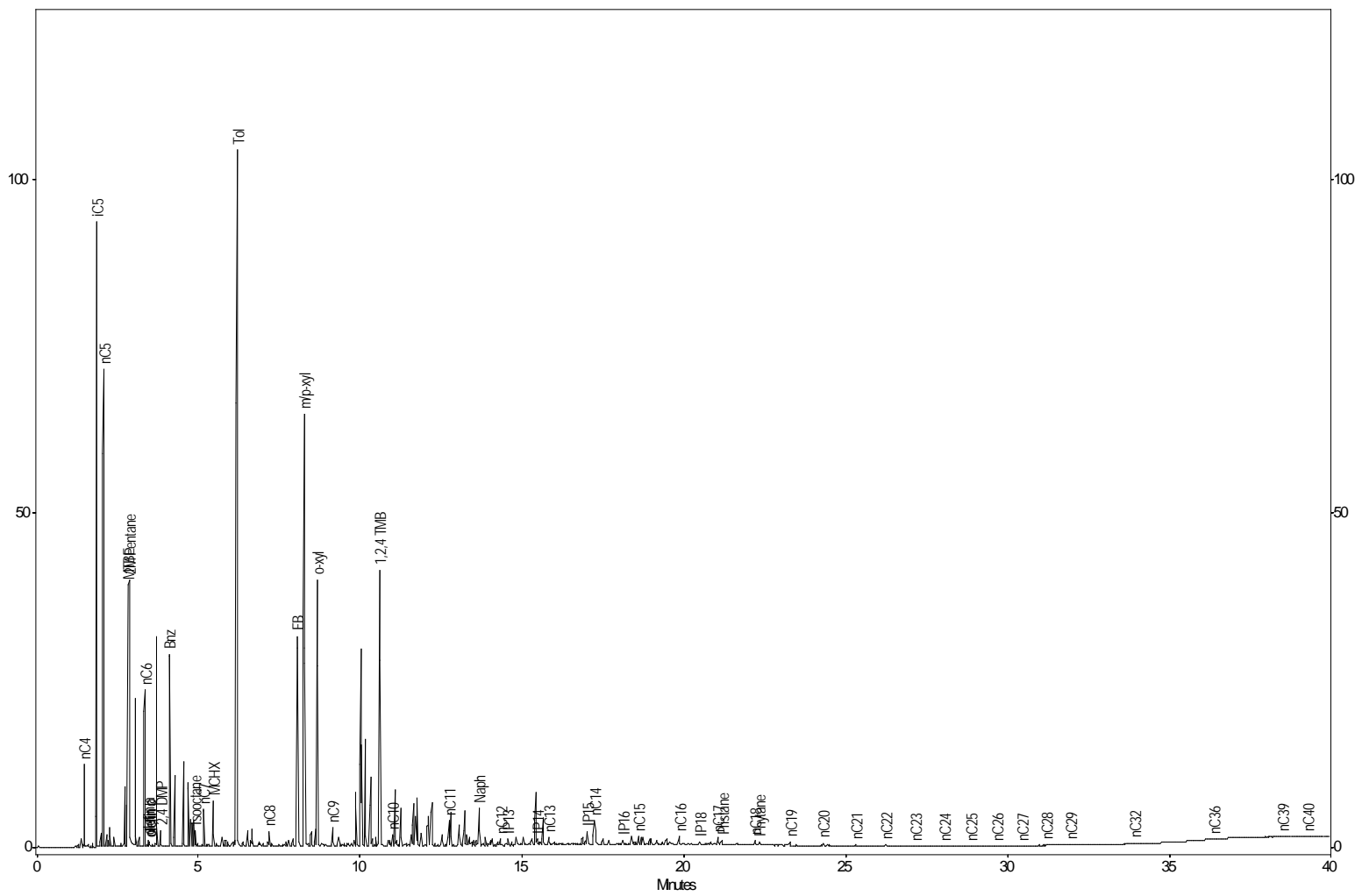

(d)

Figure 4. Fresh intermediate stream products and similar types of LNAPLs ((a) Light hydrocrackate intermediate stream product; (b) Light hydrocrackate dominated LNAPL; (c) Reformate stream product; (d) Reformate dominated LNAPL). The samples were collected from an anonymous refinery. 
wells can significantly alter the groundwater flow directions and therefore commingling of LNAPLs could occur and can be complex depending on the types of LNAPLs and hydrodynamics. In the two LNAPLs shown in Figure 4(b) and Figure 4(d), commingling is minimal so the predominant component can be identified fairly easily; however, if commingling is substantial, the LNAPL can be similar to "finished gasoline" and therefore distinction between refinery intermediate stream products and the finished gasoline becomes more challenging.

\section{Differentiation of Commingled Intermediate Stream Products from a Finished Gasoline}

At a subject petroleum refinery, LNAPL was encountered near the property boundary. Historically there were a number of refining processing units including reformers and hydrocrackers in this area. The LNAPL plume is composed of various product types. In one of the monitoring wells (MW-R), the LNAPL appears similar to the finished gasoline in which there appears to be a blend of high octane components such as aromatics (toluene, xylenes and other alkylbenzene isomers) and light molecular weight components (C5-) which arenecessary to meet RVP requirement (Figure 5). As the well is near the pipeline corridor that runs along the refinery property boundary (Figure 6), the LNAPL was thought to be a finished gasoline and sourced from the pipeline(s). However, detailed examination of the LNAPL hydrodynamics in the area, combined

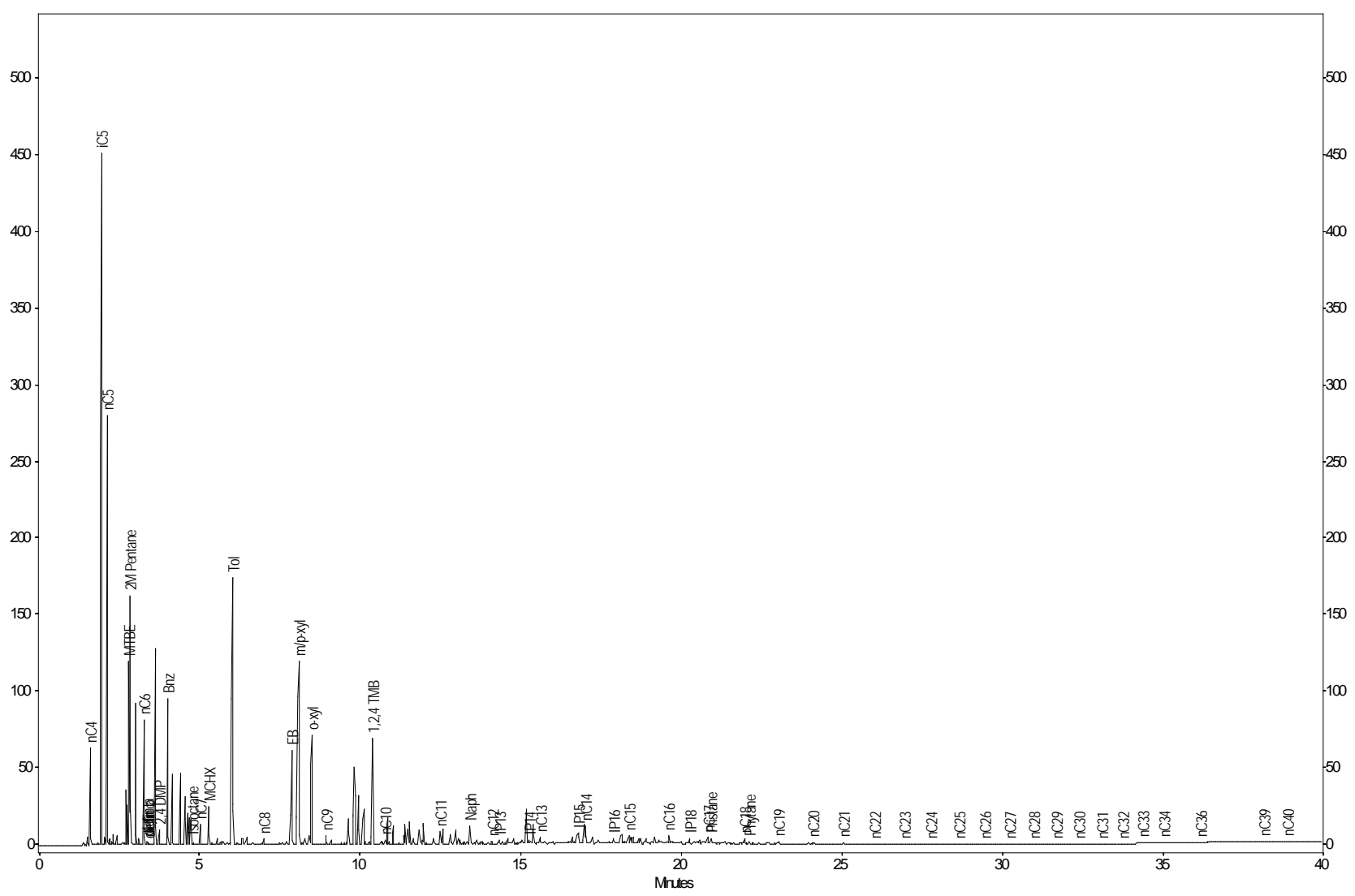

Figure 5. LNAPL in the well MW-R found in Event 2. 


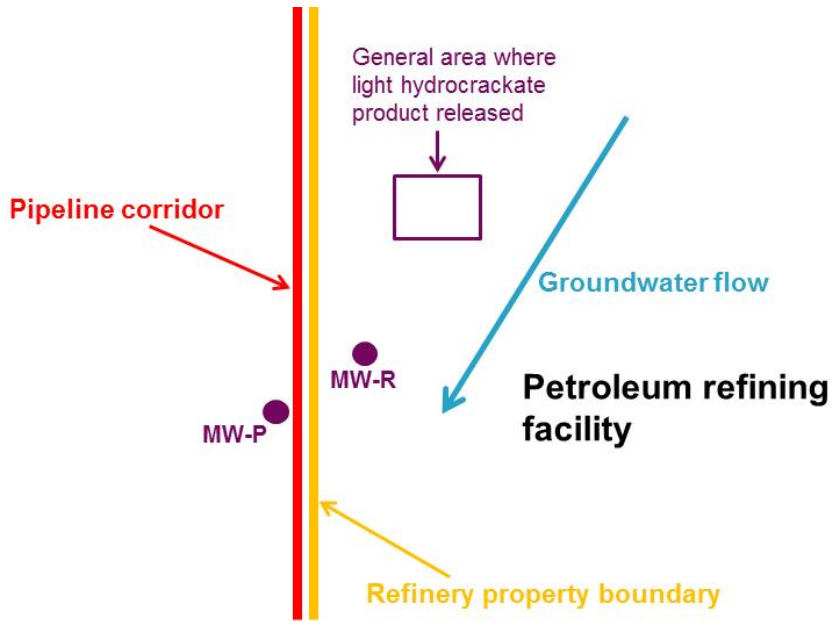

Figure 6. Site map.

with chemical characteristics of the LNAPL at MW-R suggests otherwise. Details are discussed in the following sections.

\subsection{Commingling of Gasoline Intermediate Stream Products at MW-R}

The LNAPL has been sampled from the well MW-R for a number of years for various monitoring purposes. One of the most valuable data relevant to this study is the GC/FID chromatograms. Figure 7 shows chromatograms of the LNAPL from the well. To protect client anonymity, sampling dates are not revealed; instead, they are presented sequentially as Event 1, Event 2, and Event 3. Common to all three chromatograms, similar peak patterns exist from the retention time approximately 15 minutes up. This fraction is known to be a middle distillate refinery intermediate stream (similar to No. 2 diesel). Because the middle distillate is much heavier than the gasoline range products of concern in this study and overlap of the hydrocarbons is minimal, no further discussion is made on the fraction. In the lighter fraction, three chromatograms appear different. The sample in Event lis a type of gasoline range product rich in aromatics. In Event 2 (three years later), the characteristics of LNAPL changed dramatically, with the isopentane as predominant compound. In Event 3 (two years after Event 2), the product is composed primarily of isopentane and other light molecular weight compounds $\left(\mathrm{C}_{7}^{-}\right)$. The marked change in the chemical profile mandated further investigation.

In the past, reformate stream products were released in the area where reformers were located. Release(s) of light hydrocrackate were also documented up gradient of the reformers within the refinery. Figure 8 shows comparison between LNAPL samples collected from the wells and fresh refinery intermediate stream products. As can be seen, the Event 1 product resembles reformate and Event 3 product is almost identical to the light hydrocrackate. The Event 2 sample (Figure $7(\mathrm{~d})$ ) appears to be a mixture of the two intermediate stream products. 


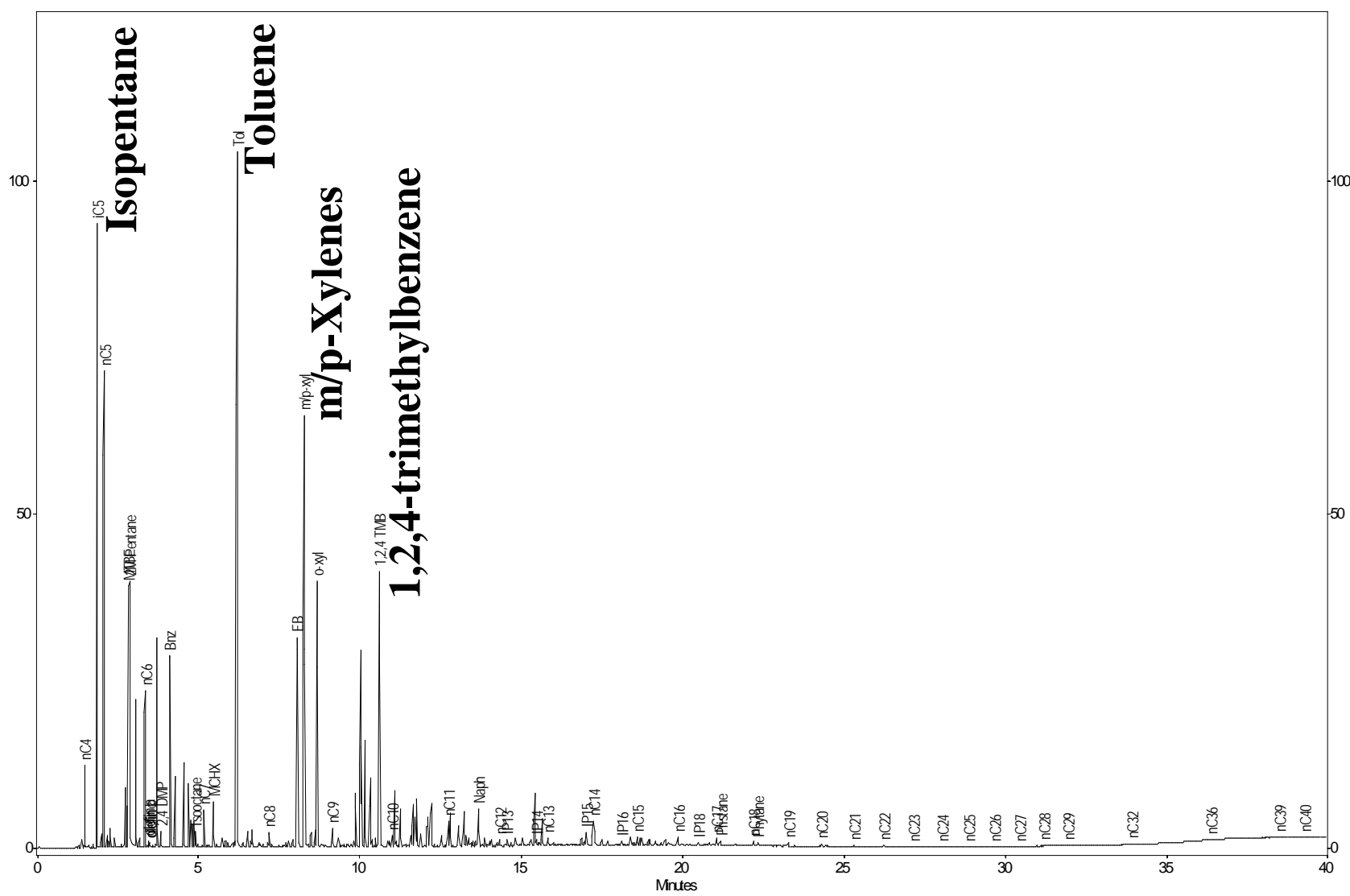

(a)

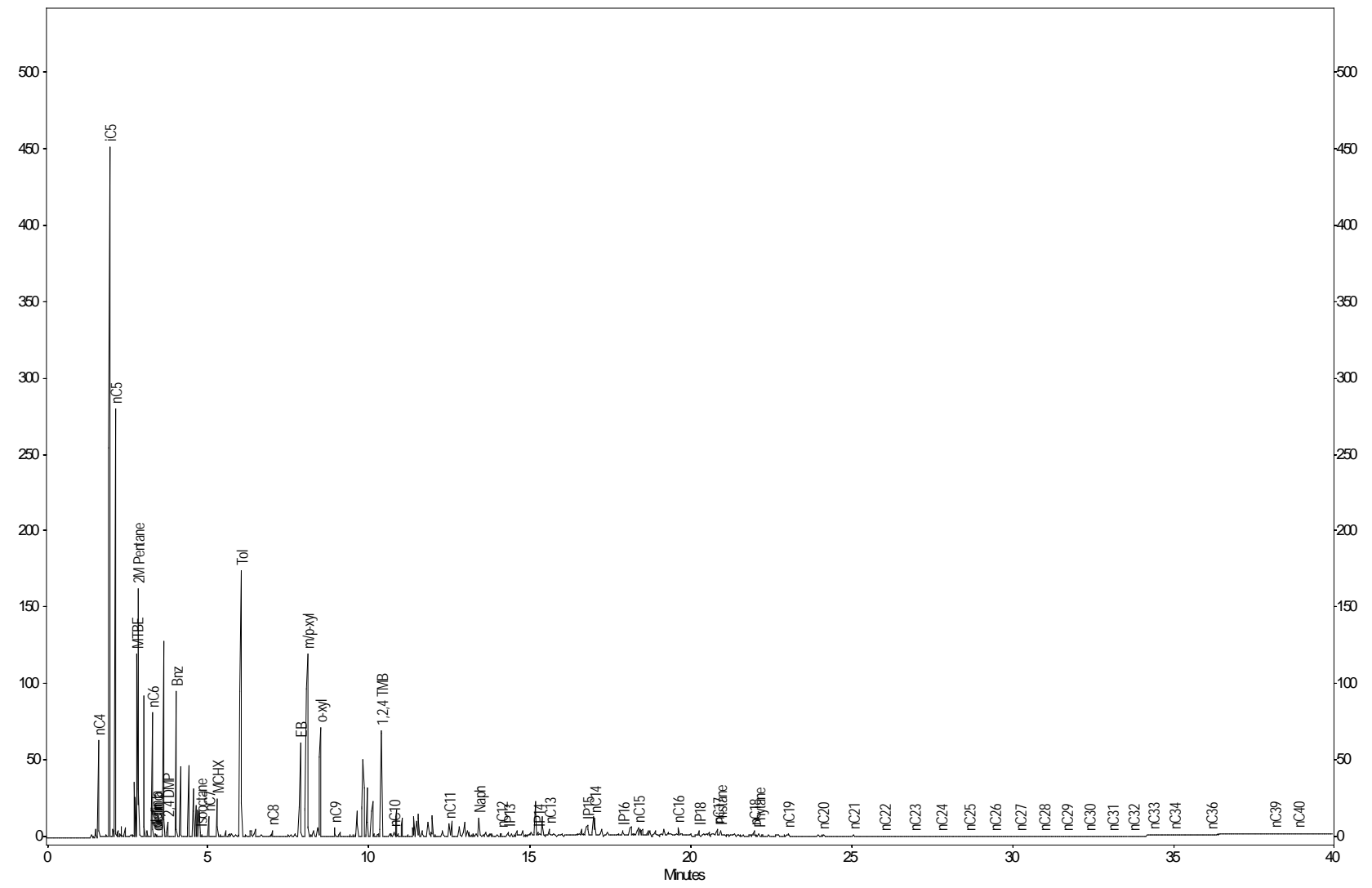

(b) 


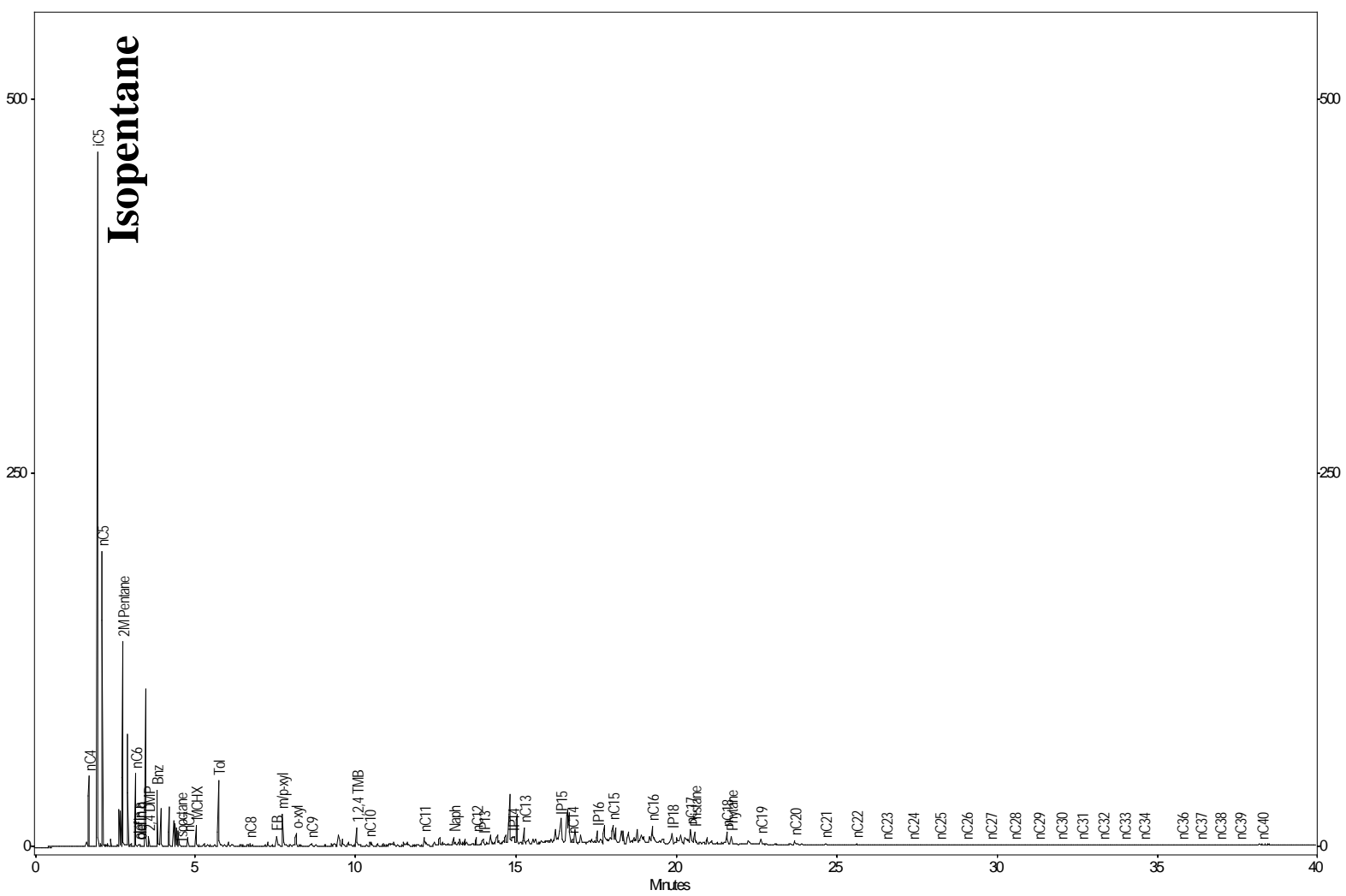

(c)

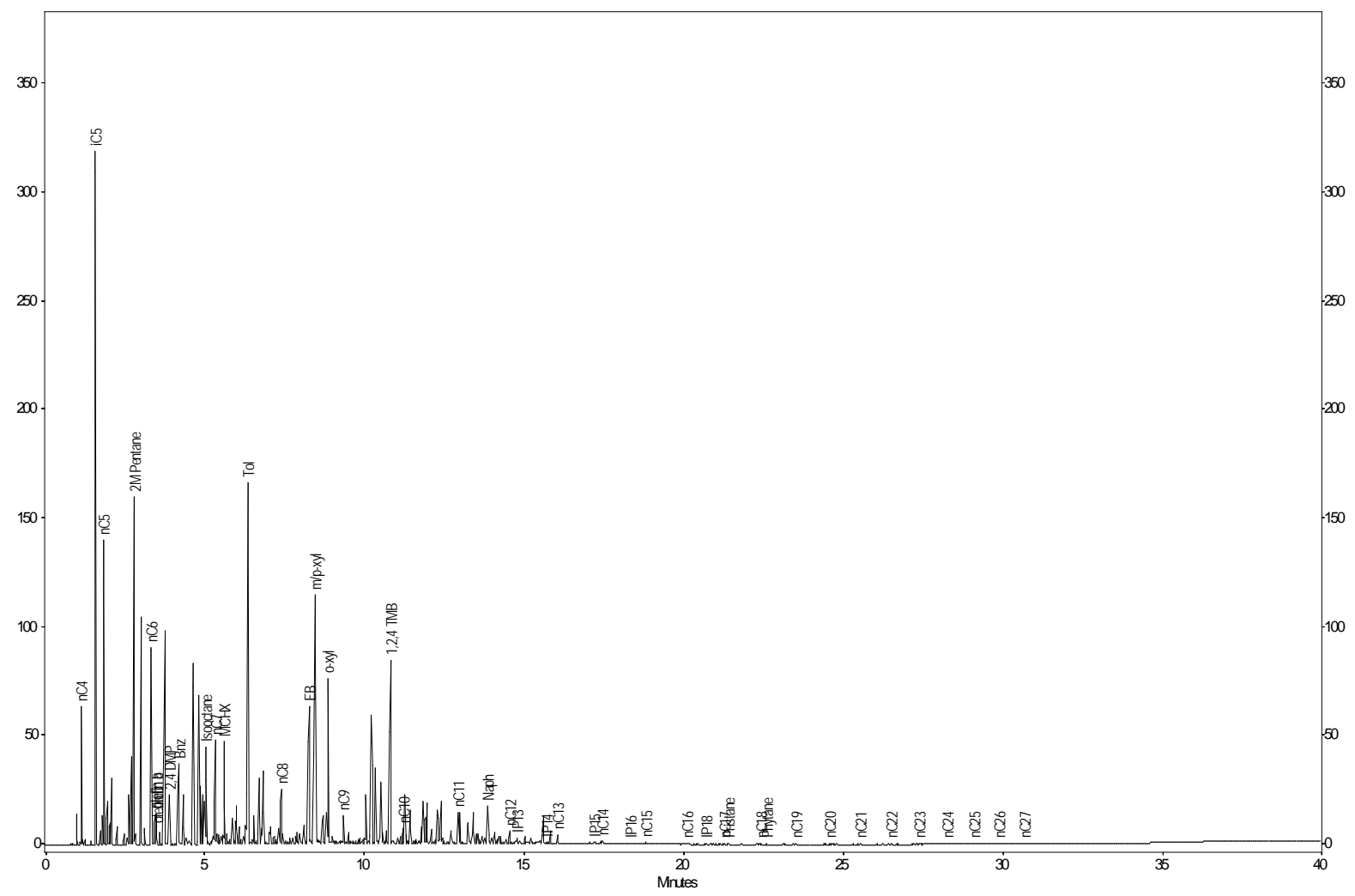

(d)

Figure 7. GC/FID chromatograms of types of LNAPL found in the well MW-R in Event 1 (a); Event 2 (b) and Event 3 (c) and the well MW-P in Event 2 (d). 


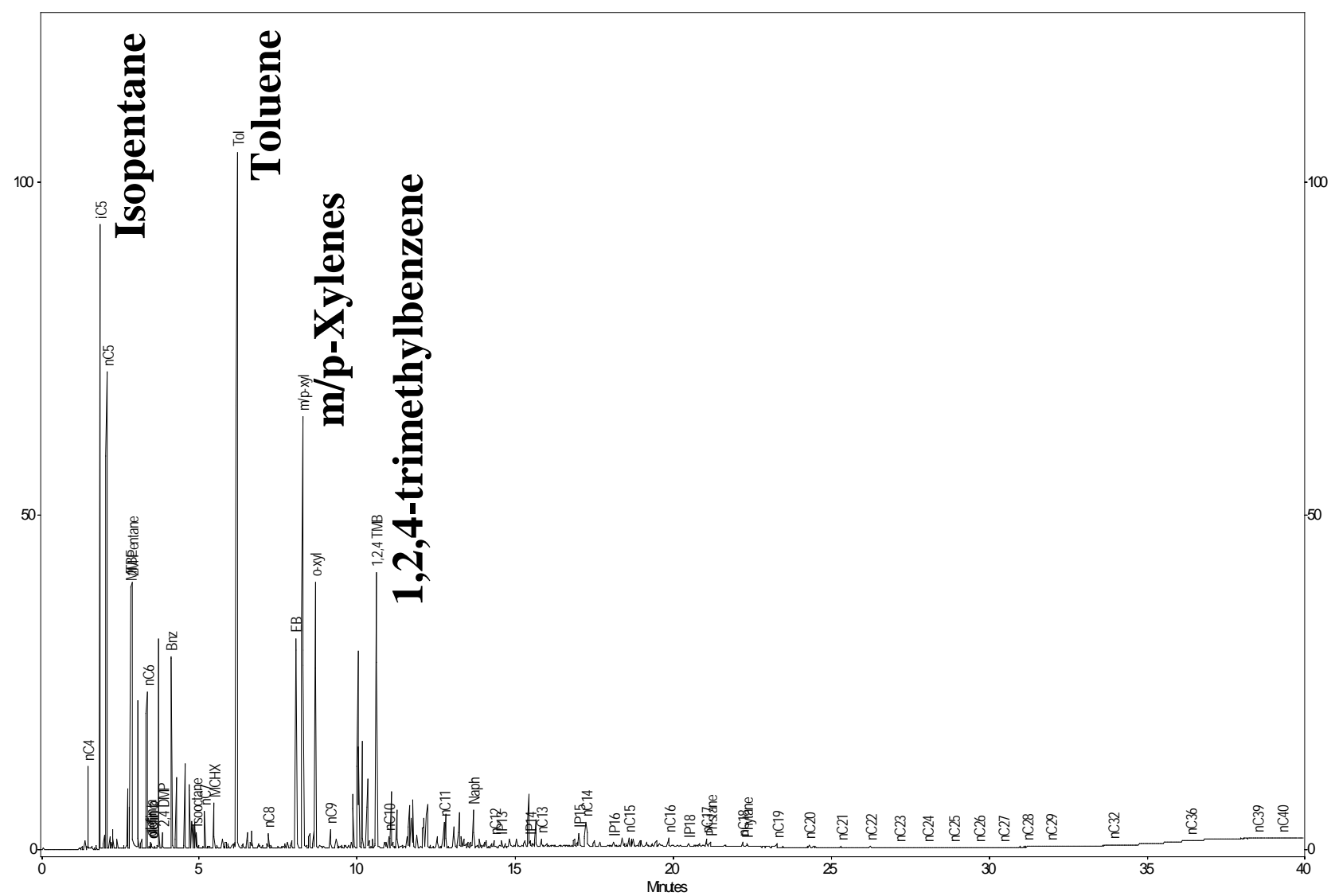

(a)

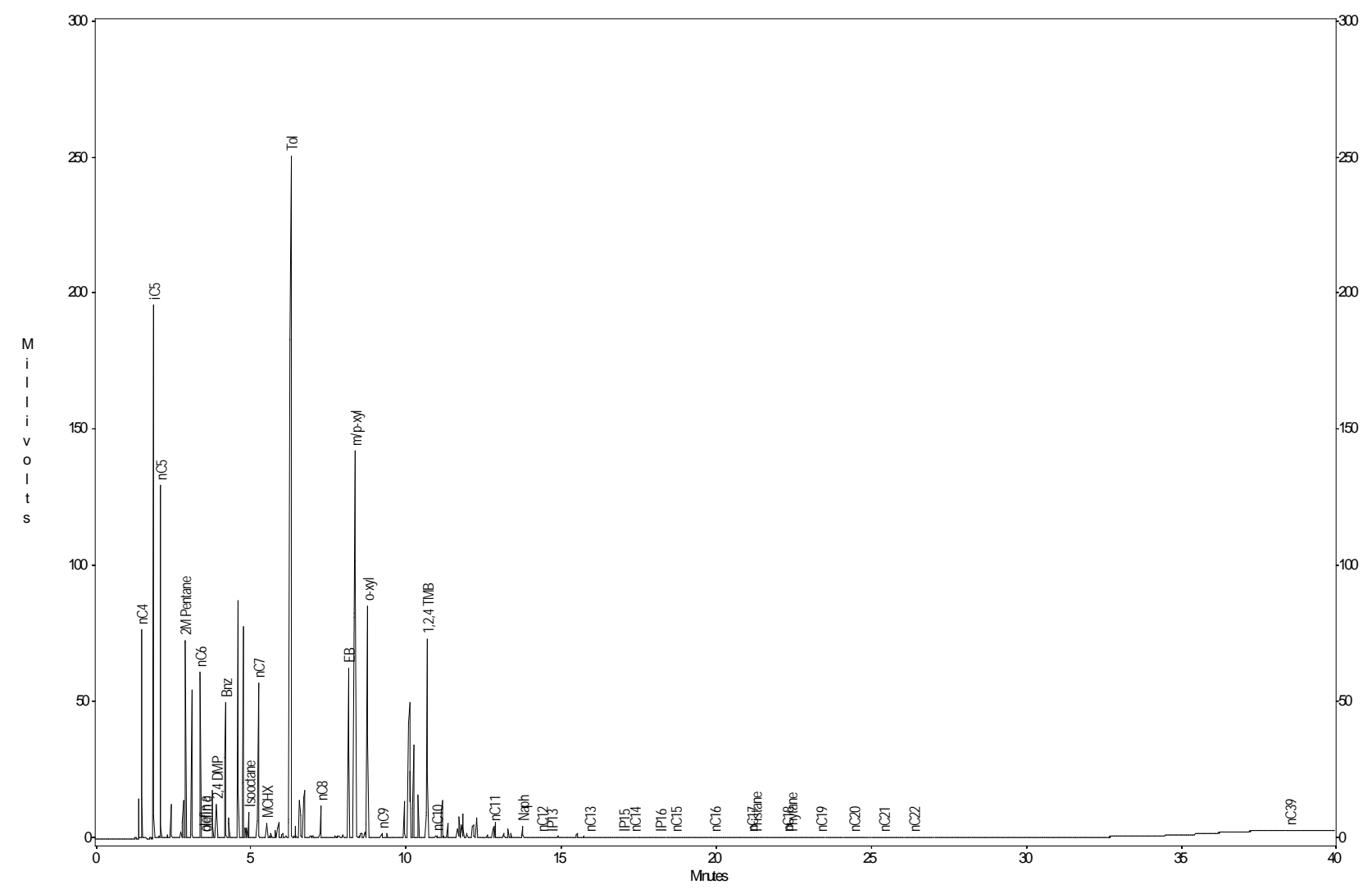

(b) 


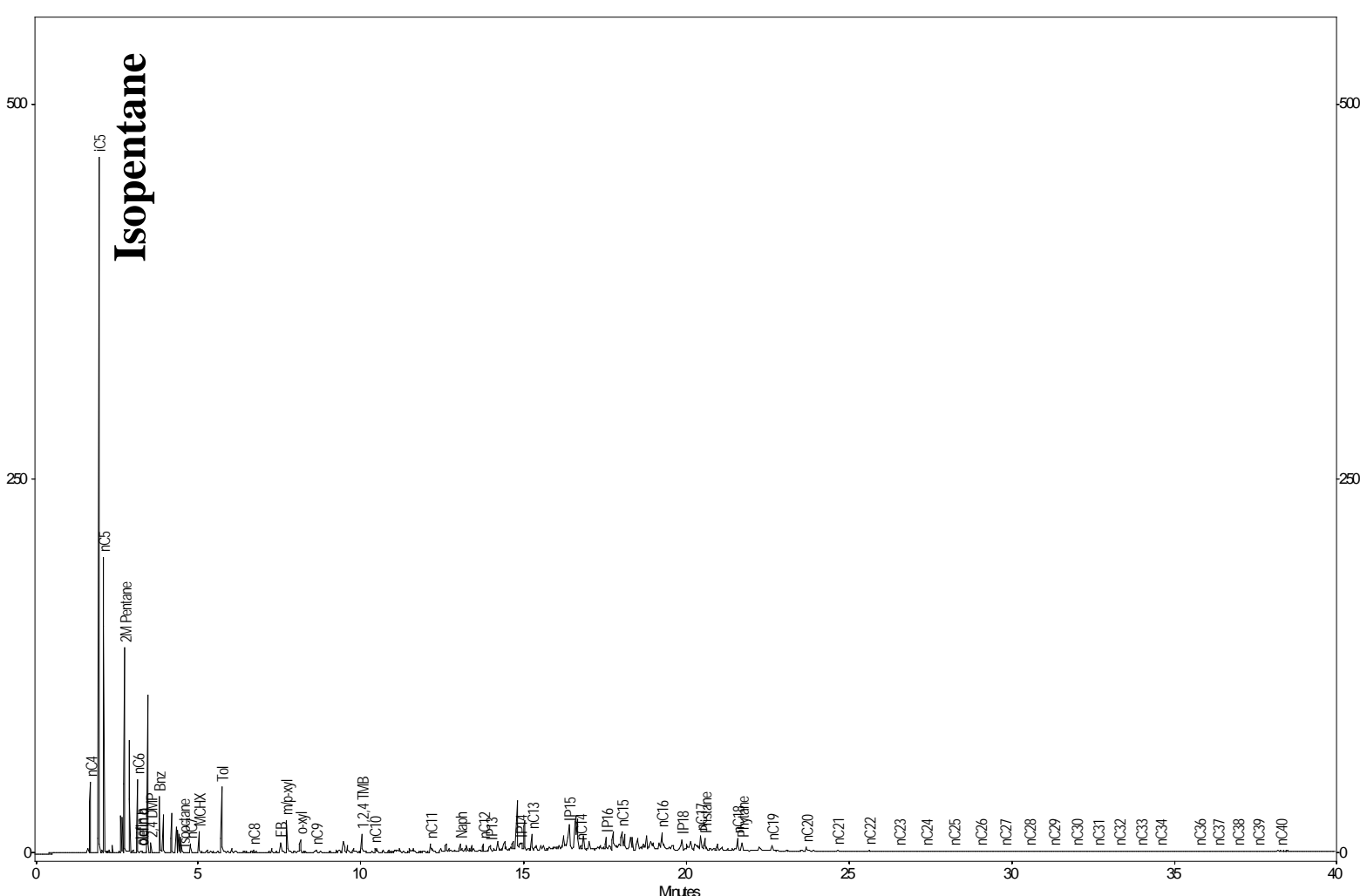

(c)

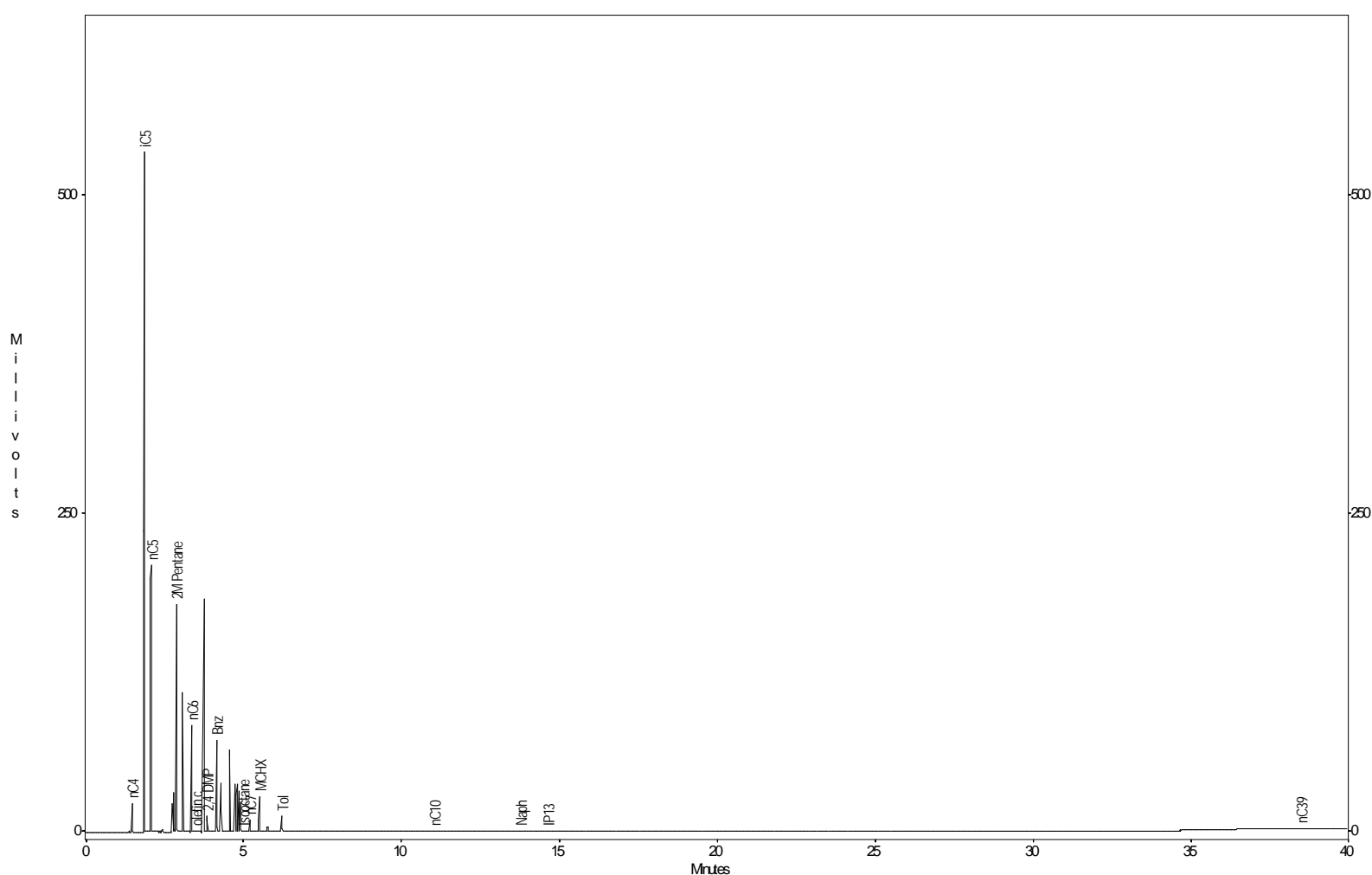

(d)

Figure 8. Comparison of LNAPLs found in the well MW-R and refinery intermediate stream products ((a) LNAPL collected in Event 1; (b) Reformate intermediate stream product; (c) LNAPL collected in Event 3; and (d) Light hydrocrackate intermediate stream product). 
The trend of the pattern change of the chemical components in the LNAPL in the consecutive events appears to indicate that the LNAPL at the well MW-R contains increasingly higher component of light hydrocrackate. This change appears to be consistent with the timing of release of light hydrocrackate (a few years prior to the time of Event 1) upgradient of the reformate LNAPL and migration of the light hydrocrackate toward the well MW-R in the direction of groundwater flow. In the area of MW-R, initial LNAPL was predominantly composed of reformate. In Event 1, the hydrocrackate LNAPL had not reached the reformate LNAPL yet and therefore the LNAPL is predominantly composed of reformate. In Event 2, light hydrocrackate from the upgradient source commingled with reformate. As shown in Figure 8, reformate is low in light molecular compounds relative to toluene; however, the addition of light hydrocrackate changed the pattern so the relative proportion of these two components become similar to those of finished gasoline. In Event 3, the original reformate LNAPL area appears to be dominated by a peak flow of light hydrocrackate, so the LNAPL in the area is predominantly light hydrocrackate.

To verify the conclusion from analysis based on LNAPL hydrodynamics, ratio analysis was conducted. Use of ratios of compounds is beneficial because with ratios concentration effects are minimized. In addition, the use of ratios tends to induce a self-normalizing effect on the data since variations due to fluctuations of instrument operating conditions, operator and matrix effects are minimized [4] [5]. For source identification or correlation between LNAPLs that have been subject to environmental alteration, the paired compounds ideally should have a similarvapor pressure, water solubility and rate of biodegradation as these are the predominant alteration mechanisms controlling LNAPL degradation in soil and groundwater.

From GC/FID analysis, relative concentrations of 89 compounds are available from laboratory reports. Of these, approximately 40 compounds are in gasoline range. Of the 40 compounds, most of them are alkylbenzene isomers. As described, the Event 3 LNAPL is predominantly composed of light hydrocrackate which contains few eligible compounds for ratio analysis and therefore is excluded. The analysis was only conducted for the samples collected in Event 1 and Event 2. For the ratio analysis, only isoalkane and aromaticisomers are considered for the reasons stated above. Out of 11 compounds, six ratios are generated and presented in Table 1.

Table 1. Ratios of selected hydrocarbon compounds.

\begin{tabular}{cccc}
\hline Ratios & MW-R-E1 & MW-R-E2 & MW-P-E2 \\
\hline 2-Methylpentane/3Methylpentane & 1.88 & 1.88 & 1.60 \\
2-Methylhexane/3Methylhexane & 1.42 & 1.55 & 1.41 \\
m/p-Xylenes/o-Xylene & 2.85 & 2.89 & 2.09 \\
1-Methyl-3-Ethylbenzene/1-Methyl-4-Ethylbenzene & 2.22 & 2.42 & 2.41 \\
1,3,5-Trimethylbenzene/1,2,4-Trimethylbenzene & 0.35 & 0.35 & 0.35 \\
1,2,4-Trimethylbenzene/1,2,3-Trimethylbenzene & 5.34 & 5.40 & 4.77 \\
\hline
\end{tabular}


As can be seen from Table 1, six ratios are identical between Event 1 and Event 2. The identical ratios suggest that the hydrocarbons in the two samples are source related and support the conclusion drawn previously.

\subsection{Characteristics of the Finished Gasoline near the Pipeline Corridor}

As described previously, a pipeline corridor runs along the refinery property boundary. During a routine groundwater monitoring event, gasoline product was present in a monitoring well (MW-P) near the boundary of a refinery facility (Figure 6). In the vicinity, only a gasoline-range LNAPL plume is represented by the LNAPL at MW-R. Figure 9 shows chromatograms of LNAPLs from both wells. On a cursory review, the LNAPLs appear similar. The lower concentration of isopentane relative to the aromatics in the MW-P could be a result of preferential depletion of isopentane due to evaporation. In fact, the LNAPL from the MW-P was claimed to be sourced from the refinery by a previous worker based on similarity of chromatographic patterns. To understand the source relationship of LNAPL from the two wells, detailed chemical fingerprints are examined and comparisons made with the LNAPL from the well MW-R.

\subsubsection{Lead Additive}

The LNAPL from the well MW-P contains organic lead (54 parts per million [ppm]), while the LNAPL from MW-R lacksorganic lead (non-detect at reporting limit of $0.5 \mathrm{ppm})$. It isunlikely the lead was sourced from the LNAPL represented by the sample from MW-R. Assuming that the LNAPL migrated from the area at or near MW-R to MW-P, the concentration of organic lead may either show little change in case of a massive LNAPL plume, or become depleted due to sorption to soils and biological and chemical processes [6] [7] [8] [9] [10]. It is possible that lead may be concentrated through preferential evaporation as the vapor pressures of lead species are lower than the light fraction of gasoline range hydrocarbons. However, this is unlikely due to deep occurrence of LNAPL as described previously. Presence of lead in the MW-P LNAPL suggests that the MW-P LNAPL is likely a leaded gasoline, but the lead content alone cannot rule out the possibility of partial contribution of MW-R LNAPL to the MW-P LNAPL.

\subsubsection{Isooctane Content}

As can be seen from Figure 9, isooctane is present in the LNAPL from well MW-P. It is possible that an alkylate LNAPL was commingled with the gasoline product at the MW-P or a component of finished gasoline intentionally blended to increase octane number. As there is no LNAPL in the vicinity that contains isooctane (including the LNAPL from the well MW-R), it is likely that the isooctane is associated with finished gasoline.

\subsubsection{Olefin Content}

Olefins consist of a group of unsaturated acyclic hydrocarbons and provided additional diagnostic fingerprints for the LNAPL at MW-P. In the chromatogram 


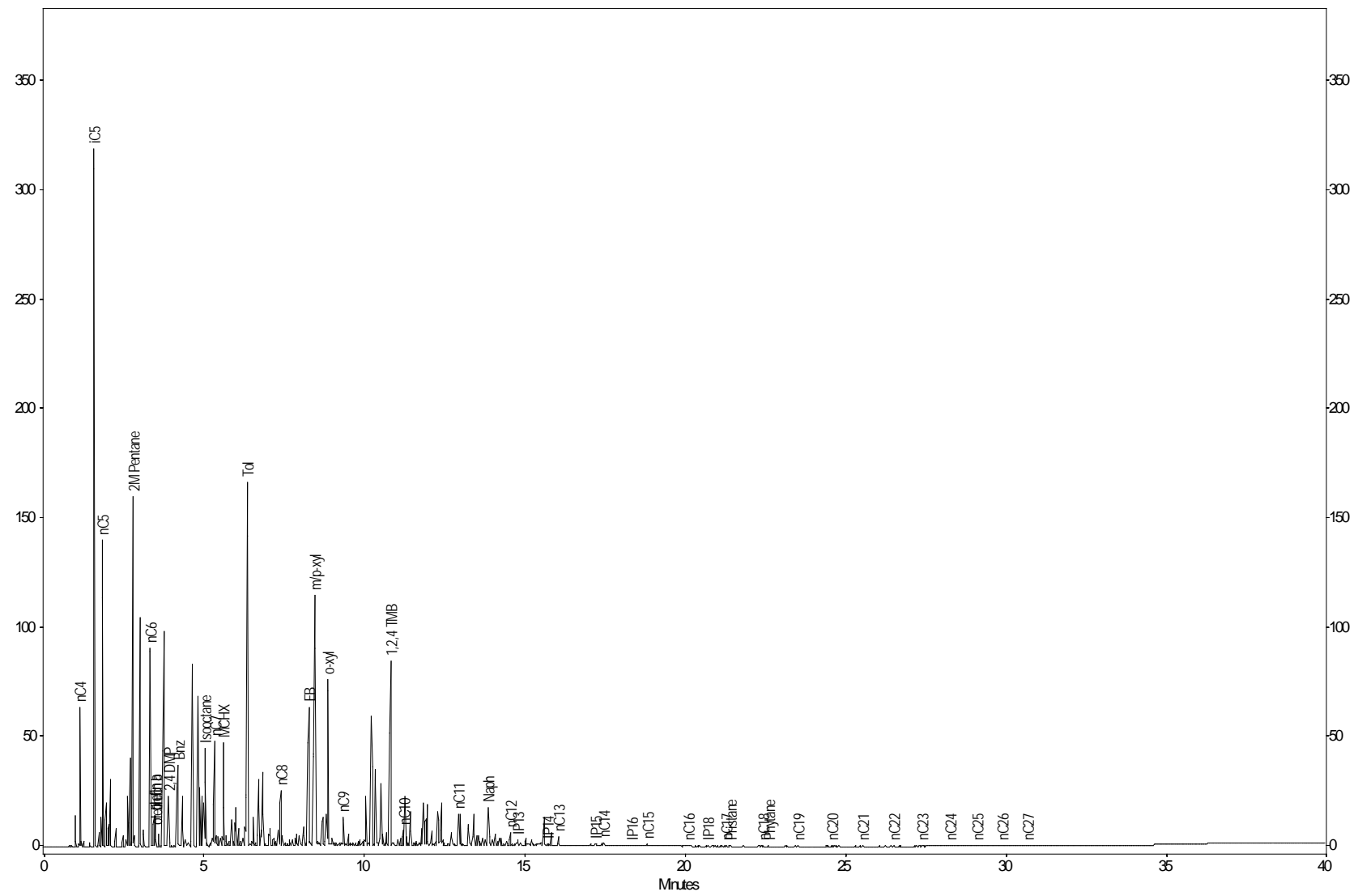

(a)

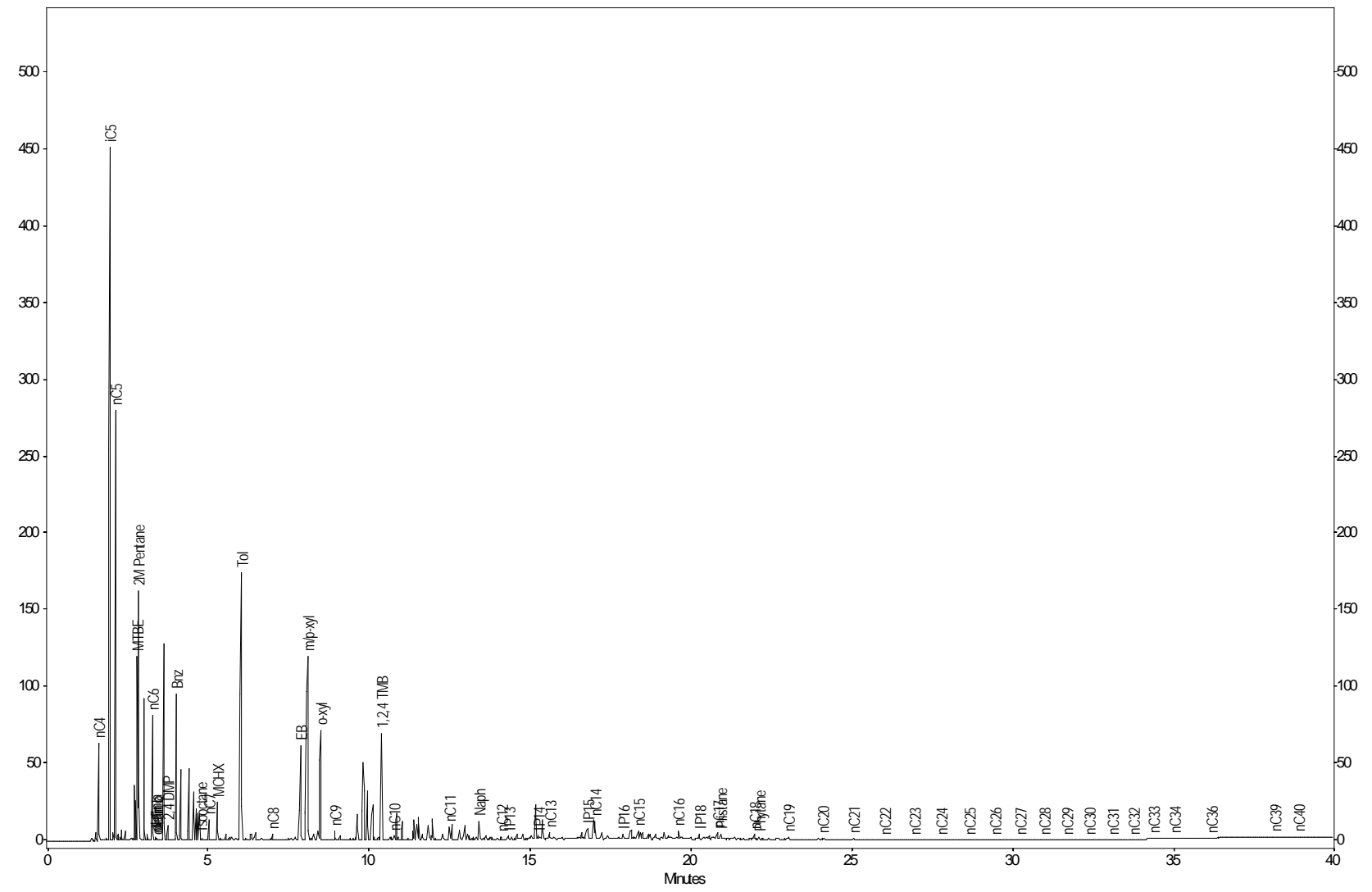

(b) 


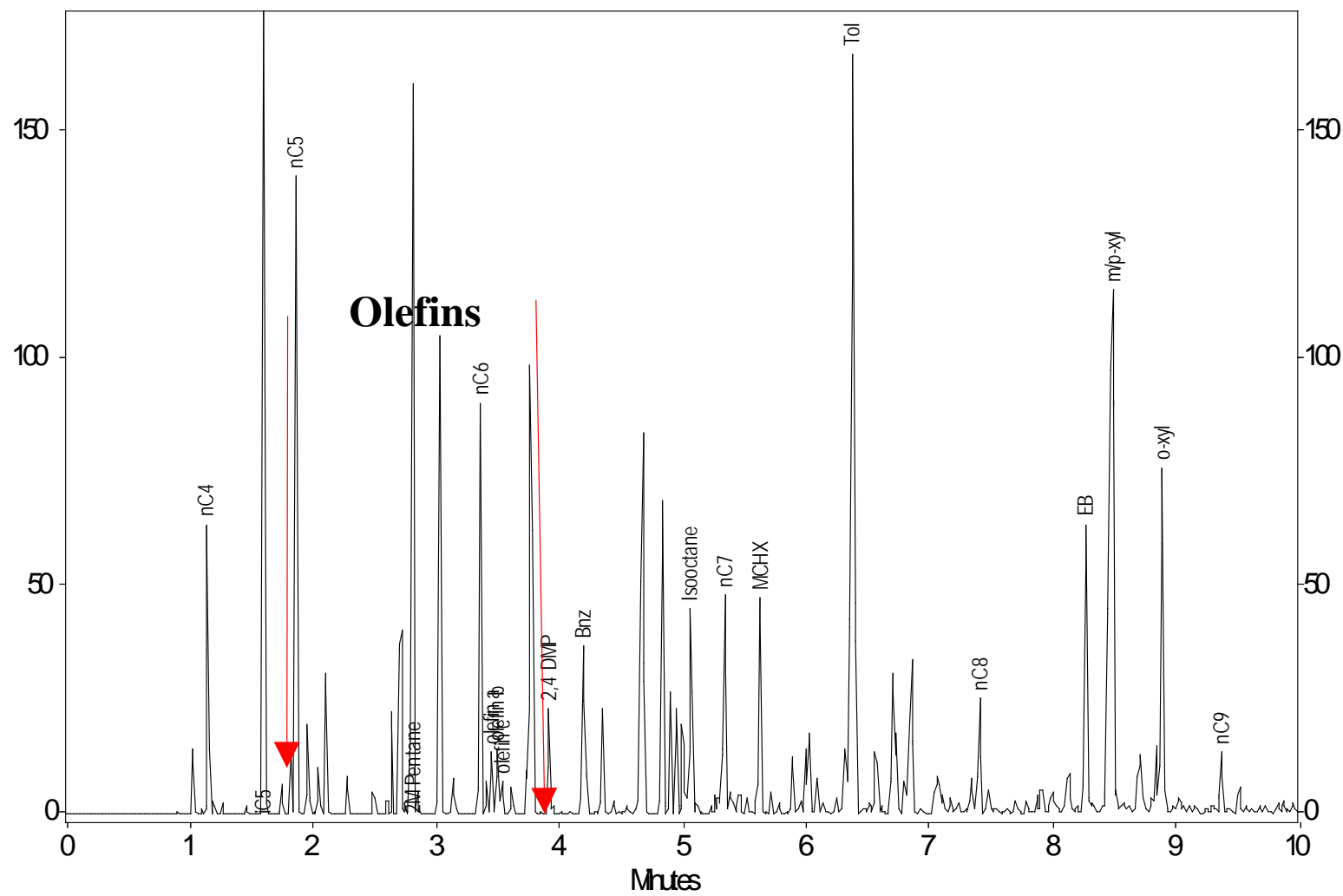

(c)

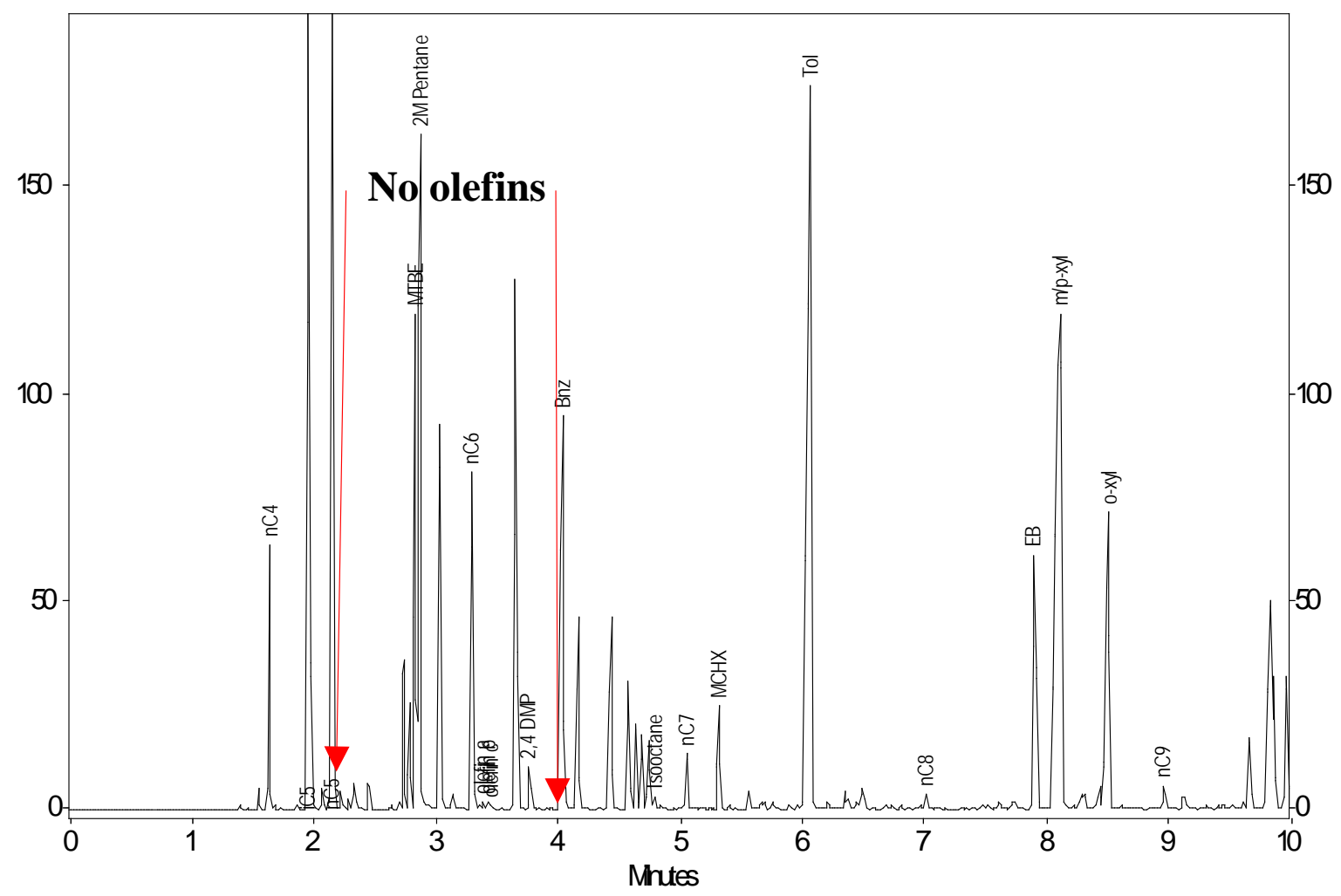

(d)

Figure 9. Contrast of olefin content in the LNAPL from the well MW-P and MW-R ((a) LNAPL from the well MW-P; (b) LNAPL from the well MW-R; (c) Expanded chromatogram of the LNAPL from MW-P; (d) Expanded chromatogram of the LNAPL from MW-R). 
of MW-P product, abundant olefins are present after nC6 and nC7 (numerous peaks) (Figure 9). However, in the chromatogram of MW-R product, olefins are either low or absent. The absence of olefins in the MW-Rindicates that the product is blended with refinery intermediate stream products by non-cracking processes except for hydrocracking, while the olefins-rich MW-P product contains an intermediate stream product that was derived from cracking processes such as fluidized catalytic cracking, thermal cracking, etc.

Olefins are known to be an unstable group of hydrocarbons due to their high reactivity as compared hydrocarbon types [11]. It is apparent that the olefins in MW-P product unlikely sourced from the MW-R product. This is because the olefins may become depleted during migration, but cannot be generated during migration.

\subsubsection{Ratios}

Ratios of selected compounds described previously were also used for comparison purposes. As can be seen from Table 1, among the six ratios, three of them (i.e, 2 methylpentane/2-methylpentane, m/p-xylenes/o-xylene and 1,2,4-trimethybenzene/1,2,3-trimethylbenzene) show significant differences among LNAPL samples ( $12 \%$ to $28 \%)$.

Each set of fingerprints presented above revealed some specific chemical characteristics of the LNAPL; collectively, the information obtained appears sufficient to conclude that the LNAPL from the well MW-P is a type of finished gasoline and sourced from the pipeline(s). The MW-R LNAPL is a result of commingling of two major gasoline intermediate stream products (i.e., reformate and light hydrocrackate) and not source-related to the MW-P LNAPL.

\section{Concluding Remarks}

This study presents a case where similar gasoline range LNAPL plumes are found in the vicinity of a refinery boundary and a major pipeline corridor. Typically, the intermediate stream products are sourced from the refinery and finished products can be either from the refinery or from other sources (e.g., pipeline corridors). As the LNAPL plumes are close to each other and both are in gasoline range, the pipeline and petroleum refinery facility both thought or claimed off-site sources for the LNAPL on their properties, however, use of multiple lines of evidence including chemical characteristics and site hydrodynamics revealed that the LNAPL from well MW-P is from the pipeline(s) and the LNAPL from well MW-R is from the refinery operations; therefore, they are not source related. This case is unique in terms of types of products and LNAPLs involved and site history and hydrogeology; however, similar disputes are quite common between pipeline owners and refinery facilities with regard to the sources of the LNAPL plumes. In areas where industries are dominated by petroleum refining facilities, it is typical that refineries and regional pipelines coexist. Understanding of the source relationship is not only critical for liability resolution, but also important for site investigation and remediation. 


\section{Acknowledgements}

The author would like to thank Kim Olsen for her editing and formatting of text, tables and figures.

\section{References}

[1] Speight, J.G. (1991) The Chemistry and Technology of Petroleum. 2nd Edition, Marcel Dekker, Inc., New York.

[2] Leffler, W.L. (2008) Petroleum Refining in Non-Technical Language. 4th Edition, PennWell Corporation, Tulsa.

[3] Weaver, J.W., Charbeneau, R.J., Tauxe, J.D., Lien, B.K. and Provost, J.B. (1994) The Hydrocarbon Spill Screening Model (HSSM). Volume 1, User's Guide, EPA/600/ R-94/039a.

[4] Wang, Z.D. and Christensen, J.H. (2006) Crude Oil and Refined Product Fingerprinting: Applications. Environmental Forensics_Contaminant Specific Guide, In: Morrison, R.D. and Murphy, B.L., Eds., Academic Press, Amsterdam.

[5] Lu, J. (2011) Chapter 8: Application of Statistics in Environmental Forensics of Fingerprinting Light Non-Aqueous Phase Liquid Data Analysis. Practical Applications of Environmental Statistics and Data Analysis, ILM Publications.

[6] Mansell, R.S., Ou, L., Rhue, R.D. and Ouyang, Y. (1995) The Fate and Behavior of Lead Alkyls in the Subsurface Environment: Final Tech. Rpt. To Armstrong Laboratory, Tyndall, Air Force Base, Battelle Memorial Institute, 102.

[7] Kaplan, I.R., Galperin, Y., Lu, S.T. and Lee, R.-P. (1997) Forensic Environmental Geochemistry: Differentiation of Fuel-Types, Their Sources and Release Time. Organic Geochemistry, 27, 289-317. https://doi.org/10.1016/S0146-6380(97)87941-7

[8] Mulroy, P.T. and Ou, L.-T. (1998) Degradation of Tetraethyllead during the Degradation of Leaded Gasoline Hydrocarbons in Soil. Environmental Toxicology and Chemistry, 17, 777-782. https://doi.org/10.1002/etc.5620170502

[9] Morrison, R.D. (2000) Critical Review of Environmental Forensic Techniques: Part II. Environmental Forensics, 1, 175-195. https://doi.org/10.1006/enfo.2000.0018

[10] Stout, S.A., Douglas, G.S. and Uhler, A.D. (2007) Chapter 18, Automotive Gasoline. Oil Spill Environmental Forensics-Fingerprinting and Source Identification, Academic Press, San Diego.

[11] Hunt, J.M. (1979) Petroleum Geochemistry and Geology. Freeman, San Francisco. 
Submit or recommend next manuscript to SCIRP and we will provide best service for you:

Accepting pre-submission inquiries through Email, Facebook, LinkedIn, Twitter, etc. A wide selection of journals (inclusive of 9 subjects, more than 200 journals)

Providing 24-hour high-quality service

User-friendly online submission system

Fair and swift peer-review system

Efficient typesetting and proofreading procedure

Display of the result of downloads and visits, as well as the number of cited articles Maximum dissemination of your research work

Submit your manuscript at: http://papersubmission.scirp.org/

Or contact jep@scirp.org 